\title{
Application of NDT apparatus for possible use as structural health monitoring of concrete building in the field
}

\author{
Akmaluddin Akmaluddin ${ }^{1, *}$, Ni Nyoman Kencanawati ${ }^{1}$, and Ahmad Gazi Paedullah ${ }^{2}$ \\ ${ }^{1}$ Postgraduate Study Program of Civil Engineering, Universitas Mataram, Mataram, Indonesia \\ ${ }^{2}$ Graduated student of Postgraduate Study Program of Civil Eng., Universitas Mataram, Indonesia
}

\begin{abstract}
A condition assessment of reinforced concrete building structures can be conducted accurately when the components of the building structure data are available. Otherwise, data must be developed through testing directly in the field. Non-Destructive Test method (NDT) was considered to avoid disruptions to the existing building structures. This study aims to develop a model for interpreting the residual strength of concrete structures in the field. Nine cylinder specimens with a diameter of $150 \mathrm{~mm}$ and a height of $300 \mathrm{~mm}$ and 27 cube specimens of 200x200x200 $\mathrm{mm}$ were prepared. Nine reinforced concrete beam specimens of $100 \times 150 \times 1100 \mathrm{~mm}$ were also prepared to represent a component of the reinforced concrete structure. Hammer and UPV apparatuses were applied to the cylinder and cube specimens considered. Results concluded that the value of the pulse velocity is directly proportional to the load and inversely proportional to the residual strength. The concrete structure with a residual strength of more than $60 \%$ is considered healthy or a structural in "good" condition. The concrete structure is also healthy when the $v$ measured gives a value of 3.5 and above. This value is acceptable as it lies within the range $v$ given in the reference of 3.5 to 4.5 .
\end{abstract}

\section{Introduction}

Testing of concrete building structures in the field is required when doubts arise about the ability of building's serviceability after the following events take place: (1) errors in the process of construction work due to low-quality control; (2) extreme load on the building due to natural disasters such as earthquakes; and (3) insufficient data for evaluating purposes if the building function is to be improved. Therefore, knowledge about the residual strength of the structure is required if the building should remain functioning. In order to satisfy these requirements, a non-destructive test on the existing building structure is required. This type of testing is referred to as the NDT method. In the following sections, the application of NDT apparatus and their study objective which are related to this topic are described.

* Corresponding author: akmaluddin@unram.ac.id 
Acoustic emission (AE) which uses high-frequency sound waves is most widely applied as a non-destructive evaluation testing technique as reviewed by Rens et al. [1,2] based on many references. An NDT technique on high strength concrete has been done experimentally by Pascale et al. [3] using velocity-based equipment type, rebound hammer, pull-out, probes penetration, micro-coring, and the combined SonReb method. These tests were verified along with destructive test techniques. Their results showed good behavior for some methods, such as pulse velocity, rebound hammer, and combined SonReb methods, and also found a relationship between dimensionless sensitivity and strength which is that sensitivity decreases with increasing strength [1].

An NDT technique using visual inspection, a perusal of drawings, ultrasonic pulse velocity measurements, cover-meter surveys, and core testing on old building structures has been carried out by Dias and Jayanandana [2]. They assessed the condition of a 30-year-old cement work, where some structures were clearly deteriorated. The important finding was a recommendation for repair and maintenance encounter (1) accumulated cement dust; (2) concrete deterioration; (3) areas experiencing elevated temperatures; and (4) waterproofing of the concrete surface.

Application of the NDT technique also can be applied to study steel bar corrosion embedded in concrete structures which are a known worldwide problem [4]. Parthiban et al. [5] measured a potential of steel embedded in concrete by developing software using visual basic 6.0 for interpretation of measured data as per ASTM C-876 for assessing the steel's condition. Another application of the NDT technique also can be used in the assessment of water content and concrete quality as reported by Breysse et al. [6]. Several available NDT methods developed and used in the last few decades have been reviewed $[2,7,8]$ and they concluded that the NDT methods are known to be better for assessing and evaluating the condition of RC structures in practice. In other words, the NDT method plays an important role in the assessment of existing structures. In addition, the NDT would benefit structural health monitoring (SHM) activities which describe various systems implemented on fullscale civil infrastructure in order to learn about either or both of the load and response mechanisms [9].

This study focuses on how to interpret the residual strength of concrete structures after loading when the material quality of the structure is questionable. For the classification required in the analysis, later on, refer to the NDT manual available [10]. To achieve the goal set out in this study, two types of NDT apparatus are used. The first is Schmidt Hammer to measure the hardness of the concrete surface and the second is Pundit which works based on ultrasonic waves for defect detection in concrete.

\section{Experimental program}

\subsection{Materials and mixture proportions}

The primarily material prepared in this investigation is a reinforcing concrete material which consisted of aggregates (sand and gravel), cement paste and reinforcing steel. Concrete compressive strength considered was 25,35 and $45 \mathrm{MPa}$ as a representation of normal concrete. The bar reinforcement used was steel with a yield strength of $250 \mathrm{MPa}$. Prior to the design of the concrete mixes, the initial examination of the aggregate properties was carried out and have found to meet Indonesian standard, SNI-7656-2012 [11].

To achieve the concrete strength specified above, concrete mix design has been undertaken. The water to cement ratio set for the specified concrete of 25,35 and $45 \mathrm{MPa}$ were $0.56,0.48$ and 0.43 respectively. For more details, the cement and aggregate proportions for the $1 \mathrm{~m}^{3}$ mixture are listed in Table 1 below. 
Table 1. Concrete mix proportions for $1 \mathrm{~m}^{3}$

\begin{tabular}{|c|c|c|c|}
\hline \multirow{2}{*}{ Description } & \multicolumn{3}{|c|}{ Compressive strength (MPa) } \\
\cline { 2 - 4 } & $\mathbf{2 5}$ & $\mathbf{3 5}$ & $\mathbf{4 5}$ \\
\hline Water to cement ratio & 0.56 & 0.48 & 0.43 \\
\hline Cement $\left(\mathrm{kg} / \mathrm{m}^{3}\right)$ & 360 & 427 & 466 \\
\hline Water $\left(\mathrm{kg} / \mathrm{m}^{3}\right)$ & 205 & 205 & 205 \\
\hline Sand $\left(\mathrm{kg} / \mathrm{m}^{3}\right)$ & 740 & 713 & 693 \\
\hline Gravel $\left(\mathrm{kg} / \mathrm{m}^{3}\right)$ & 1110 & 1070 & 1040 \\
\hline
\end{tabular}

\subsection{Test specimens and schedule}

Eighteen specimens consisting of 9 concrete cubes of 200x200x200 $\mathrm{mm}$ in size and 9 cylinders of concrete with a diameter size of $150 \mathrm{~mm}$ and a height of $300 \mathrm{~mm}$ were

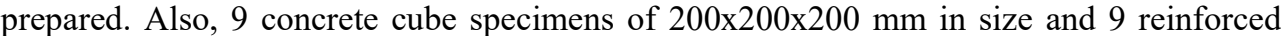
concrete beam specimens of 100x150x1100 mm were considered. These specimens were divided into three groups, namely Group 1, Group 2 and Group 3 respectively. Group 1 was intended to develop a compressive strength relationship between concrete cylinders and concrete cubes using a standard destructive test. Group 2 was aimed to find the relationship of concrete strength with pulse velocity and the rebound number. For this objective of testing, it was conducted by combining the NDT and DT testing methods. For the NDT test method, it was carried out by applying UPV and Hammer test equipment. Group 3 was intended to validate the model developed. This specimen was assumed to represent structural concrete components in the field. The specimen grouping, designation and total number required are presented in Table 2 .

Table 2. Grouping specimen information

\begin{tabular}{|c|c|c|c|}
\hline Group & Designation*) & $\begin{array}{c}\text { Specimen } \\
\text { number }\end{array}$ & Type of test \\
\hline \multirow{6}{*}{1} & $\mathrm{C}-25$ & 3 & \multirow{6}{*}{$\begin{array}{l}\text { Compression test: Destructive } \\
\text { test (DT) using compression test } \\
\text { machine }\end{array}$} \\
\hline & $\mathrm{C}-35$ & 3 & \\
\hline & C-45 & 3 & \\
\hline & $\mathrm{Cu}-25$ & 3 & \\
\hline & $\mathrm{Cu}-35$ & 3 & \\
\hline & $\mathrm{Cu}-45$ & 3 & \\
\hline \multicolumn{2}{|r|}{ Total 1} & \multicolumn{2}{|c|}{$18=(9 \mathrm{C}$ and $9 \mathrm{Cu})$} \\
\hline \multirow{3}{*}{2} & $\mathrm{Cu}-25$ & 3 & \multirow{3}{*}{$\begin{array}{l}\text { Compression test: DT as above } \\
\text { alongside NDT using Pundit and } \\
\text { Rebound Hammer }\end{array}$} \\
\hline & $\mathrm{Cu}-35$ & 3 & \\
\hline & $\mathrm{Cu}-45$ & 3 & \\
\hline \multicolumn{2}{|r|}{ Total 2} & \multicolumn{2}{|l|}{9} \\
\hline \multirow{3}{*}{3} & B-25 & 3 & \multirow{3}{*}{$\begin{array}{l}\text { Flexural test simultaneously } \\
\text { with NDT testing }\end{array}$} \\
\hline & B-35 & 3 & \\
\hline & B-45 & 3 & \\
\hline & Total 3 & 9 & \\
\hline
\end{tabular}

Group 1 was scheduled for preliminary testing using cylinder and cube specimens. This test was carried out destructively and produced a relationship between cylinders and cubes in terms of their strength and elastic modulus. This result also can be used to estimate the maximum load capacity acting on the specimens in Group 2.

Group 2 followed the schedule which simultaneously combined compression tests destructively and NDT tests by applying Pundit and Hammer apparatuses. The NDT test 
was carried out at a certain load level about of $0,25 \%, 50 \%, 75 \%$ and $100 \%$ of the maximum load (estimated previously of Group 1). The testing set up for Group 2 is shown in Fig. 1(a).

Finally, Group 3 was set to represent a real condition of the structure in the field, especially member in flexure. The NDT test was applied simultaneously with loading. Through the simple analysis, the maximum load capacity of the member was estimated and the NDT test was given at a certain load level of the maximum load. Both in Group 2 and 3, Pundit apparatus was applied first followed by the Hammer in the same position. Fig. 1(b) shows the details of the test set-up of Group 3.

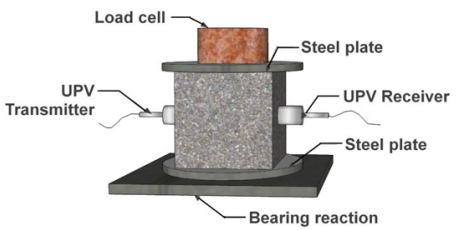

(a)

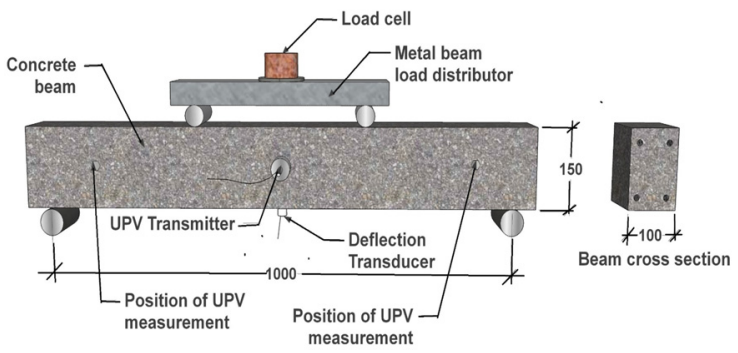

(b)

Fig. 1. Sketch of testing set-up specimen under (a) compression and (b) flexural

\subsection{Batching, casting and curing}

To make sure the concrete strength specified was achieved care was taken to maintain the concrete mix proportion as in Table 1 . A rotary drum mixer with a capacity of $0.05 \mathrm{~m}^{3}$ alongside cylinder, cube, and beam molds were prepared. The coating had been done using a lubricant to avoid attachment of the concrete to the mold. The inside of the mixer was moistened prior to the mix. The gravel, sand, and cement were mixed in a dry condition. Water was added as specified then stirred until the mixture was evenly distributed. After the mixture was ready, specimens were cast by pouring the concrete mixture into the prepared mold. Twenty-four hours after casting, the specimens were removed and the concrete cylinder and cube specimens immersed in the water tank for 27 days as per SNI [11]. For the beam specimen, after removing, the specimens were cured by spraying water every day and covering them with wet burlap and polyethylene sheets at room temperature.

A day before testing was carried out, the cylinder and cube specimens were removed from the water tank. For the beam specimens, the burlap and plastic sheets were also removed. All specimens were left to dry at room temperature.

\section{Experimental results and discussions}

All experimental results are presented and discussed sequentially based on the groupings of tests that have been specified as mentioned in the previous section.

\subsection{Compressive strength and elastic modulus}

The compression tests performed on 9 cylinder and 9 cube specimens (Group 1) produced the following results as shown in Table 3. It is clear from the table that all compressive strength based on the cylinder specimen has a value lower than that of the cube specimen as shown by the ratio of less than 1.00 or an average of 0.92 . The ratio varies between 0.81 and 0.99 as shown in column (5) in the table. 
Table 3. Variation of compressive strength and modulus of elasticity values

\begin{tabular}{|c|c|c|c|c|c|c|c|c|c|}
\hline \multicolumn{4}{|c|}{ Compressive strength (MPa) } & \multirow{2}{*}{ Ratio } & \multicolumn{4}{|c|}{ Modulus of elasticity (MPa) } & \multirow{3}{*}{$\begin{array}{c}\text { Ratio } \\
(10)\end{array}$} \\
\hline \multicolumn{2}{|c|}{ cylinder } & \multicolumn{2}{|c|}{ cube } & & \multicolumn{2}{|c|}{ Ec, cylinder } & \multicolumn{2}{|c|}{ Ed, Cube } & \\
\hline (1) & (2) & (3) & (4) & (5) & (6) & (7) & (8) & (9) & \\
\hline $\mathrm{C}-25_{1}$ & 21.94 & $\mathrm{Cu}-25_{1}$ & 24.91 & 0.88 & $\mathrm{C}-25_{1}$ & 28,378 & $\mathrm{Cu}-25_{1}$ & 39,193 & 0.72 \\
\hline $\mathrm{C}-25_{2}$ & 20.28 & $\mathrm{Cu}-25_{2}$ & 24.91 & 0.81 & $\mathrm{C}-25_{2}$ & 25,138 & $\mathrm{Cu}-25_{2}$ & 35,595 & 0.71 \\
\hline $\mathrm{C}-25_{3}$ & 22.35 & $\mathrm{Cu}-25_{3}$ & 26.61 & 0.84 & $\mathrm{C}-25_{3}$ & 26,697 & $\mathrm{Cu}-25_{3}$ & 36,698 & 0.73 \\
\hline $\mathrm{C}-35_{1}$ & 38.39 & $\mathrm{Cu}-35_{1}$ & 40.20 & 0.95 & $\mathrm{C}-35_{1}$ & 33,631 & $\mathrm{Cu}-35_{1}$ & 41,182 & 0.82 \\
\hline $\mathrm{C}-35_{2}$ & 38.50 & $\mathrm{Cu}-35_{2}$ & 40.20 & 0.96 & $\mathrm{C}-35_{2}$ & 30,321 & $\mathrm{Cu}-35_{2}$ & 40,576 & 0.75 \\
\hline $\mathrm{C}-35_{3}$ & 34.99 & $\mathrm{Cu}-35_{3}$ & 35.10 & 0.99 & $\mathrm{C}-35_{3}$ & 33,631 & $\mathrm{Cu}-35_{3}$ & 41,335 & 0.81 \\
\hline C- $45_{1}$ & 40.20 & $\mathrm{Cu}-45_{1}$ & 45.86 & 0.88 & C- $455_{1}$ & 33,285 & $\mathrm{Cu}-45_{1}$ & 45,377 & 0.73 \\
\hline C- $45_{2}$ & 42.01 & $\mathrm{Cu}-45_{2}$ & 43.60 & 0.96 & $\mathrm{C}-45_{2}$ & 35,106 & $\mathrm{Cu}-45_{2}$ & 50,945 & 0.69 \\
\hline $\mathrm{C}-45_{3}$ & 43.79 & $\mathrm{Cu}-45_{3}$ & 45.58 & 0.96 & $\mathrm{C}-45_{3}$ & 31,622 & $\mathrm{Cu}-45_{3}$ & 44,801 & 0.71 \\
\hline \multicolumn{4}{|c|}{ average } & 0.92 & \multicolumn{4}{|c|}{ average } & 0.74 \\
\hline
\end{tabular}

The relationship between the cylinder and the cube strength are shown in Fig. 2(a). In general, a linear and strong relationship is found, as shown by the value of $\mathrm{R}^{2}$ approaching 1. This relationship is further expressed in the form of Eq. (1) below:

$$
f_{c}^{\prime}=0.9313 f_{c u}
$$

where $f_{c}^{\prime}$ and $f_{c u}$ are the cylinder and the cube compressive strength respectively.

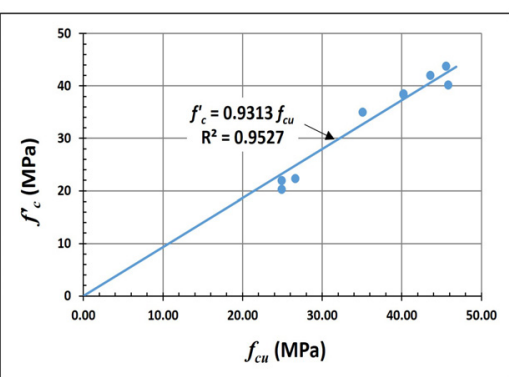

(a)

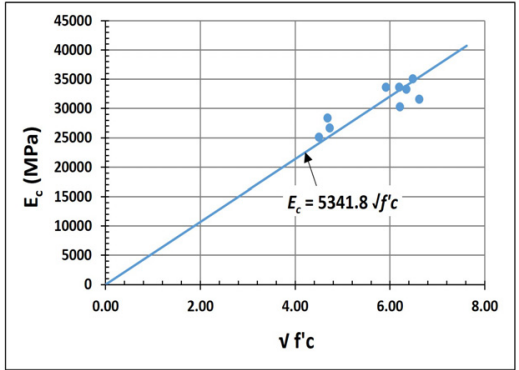

(b)

Fig. 2. (a) Comparison of the cylinder and cube strength; (b) Development of $E_{c}$

The modulus of elasticity is obtained experimentally from a standard test of cylinder specimens using Eq. (2) [12].

$$
E_{c}=\frac{S_{2}-S_{1}}{\varepsilon_{2}-0.00005}
$$

where $E_{c}$ is the modulus of elasticity, $S_{2}$ is the stress corresponding to $40 \%$ of the ultimate load, $S_{1}$ is stress corresponding to a longitudinal strain of 0.00005 , and $\varepsilon_{2}$ is the longitudinal strain produced by stress $S_{2}$.

The relationship between the modulus of elasticity versus the square root of the compressive strength is plotted in Fig. 2(b). A linear relationship is also found and presented as Eq. (3) below. 


$$
E_{c}=5342 \sqrt{f_{c}^{\prime}}
$$

When the cube strength $\left(f_{c u}\right)$ data are available, to subsequently obtain the static modulus of elasticity, Eq. (1) must be applied first before applying Eq. (3); otherwise Eq. (4) is used.

$$
E_{c}=5155 \sqrt{f_{c u}}
$$

Identical to the compressive strength, the relationship between static modulus of elasticity, $E_{c}$, and dynamic modulus of elasticity, $E_{d}$ is obtained and presented as Eq. (5).

$$
E_{c}=0.74 E_{d}
$$

When velocity data are available instead of $E_{d}$ then Eq. (5) can be used after $E_{d}$ is obtained using Eq. (6) [10, 13].

$$
E_{d}=\frac{\rho v^{2}(1+v)(1-2 v)}{(1-v)}
$$

where $E_{d}$ is the dynamic elastic modulus $\left(\mathrm{MN} / \mathrm{m}^{2}\right), v$ is the dynamic Poisson's ratio, $\rho$ is the density $\left(\mathrm{kg} / \mathrm{m}^{3}\right)$ and $v$ is the pulse velocity $(\mathrm{km} / \mathrm{s})$. In this case, $v$ is taken as 0.18 and $\rho$ is $2381 \mathrm{~kg} / \mathrm{m}^{3}$.

\subsection{UPV and rebound number}

Both the Pundit and Hammer test results give similar trends in terms of pulse velocity and rebound number respectively for various compressive strengths which are higher as the specimen strength increases. However, their values decreased as the percentage of loading increased as shown in Fig. 3(a).

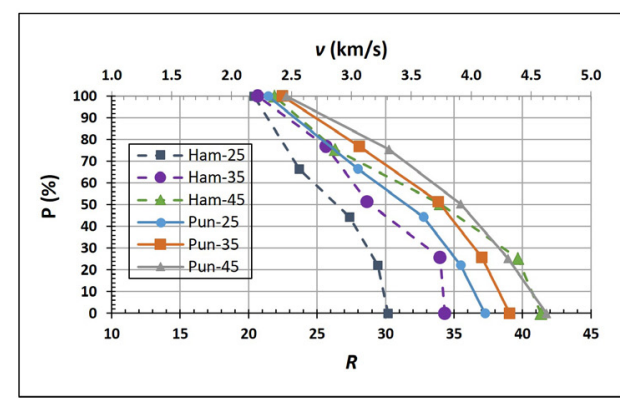

(a)

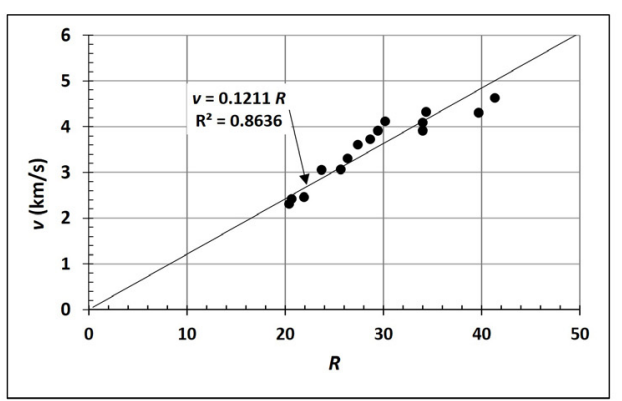

(b)

Fig. 3. (a) Percentage load acting against $v$ and $R$; (b) $v$ and $R$ relationship

As a measurement for both apparatus is applied in the same specimen and places, then their reading relationship between pulse velocity and rebound number can be generated as plotted in Fig. 3(b) above. It can be said from the figure that the pulse velocity is about $12 \%$ of the rebound number. This can also be written as Eq. (7).

$$
v=0.1211 R
$$

in which $v$ is the pulse velocity $(\mathrm{km} / \mathrm{s})$ and $R$ is the rebound number reading from the Hammer apparatus. This equation could be used to generate interpretation about the structure condition when the rebound number data are available. 
In order to draw a more comprehensive conclusion then all readings of pulse velocity (v) against the percentage of load given for the three variations of concrete compressive strength for both direct and indirect method are plotted and presented as Fig. 4(a). The velocity value by the direct method is slightly higher than that of the indirect method along the increased percentage of load given. The trend is quite similar to each other. In general, for both methods the increased load produced a decreased velocity.

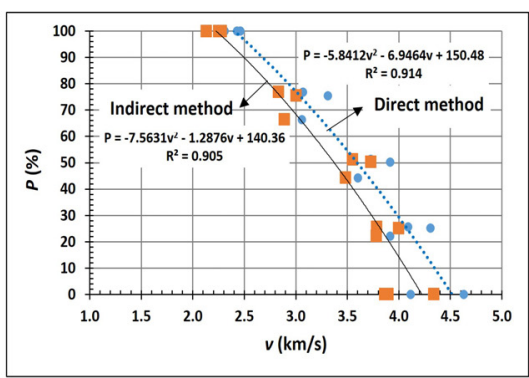

(a)

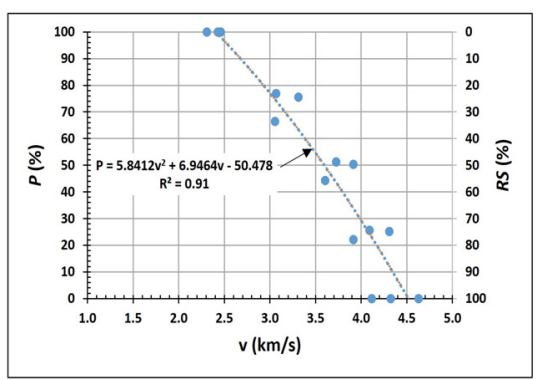

(b)

Fig. 4. Percentage load acting against $v$ : (a) different scanning method; (b) direct method showing residual strength (RS)

\subsection{Residual strength and concrete classification}

When the residual strength $(R S)$ is introduced in this paper and it is defined as the difference between the maximum strength of the structure and the strength that is being experienced, then the possible load that may be added to the structure can be estimated in terms of structural safety. For example, the cylinder reaches its maximum load which is equivalent to $100 \%$ loading, then the cylinder is given a load equivalent to $30 \%$ of its maximum load so the residual strength $(R S)$ of the cylinder is 100 minus 30 equalling $70 \%$. This definition is presented as the secondary y-axis as shown in Fig. 4(b) for the direct method given previously in Fig. 4(a).

From Fig. 4(b) it can be said in general that the pulse velocity $(v)$ is directly proportional to the concrete residual strength $(R S)$ and inversely proportional to the percentage of load. In another word, the greater the value of $v$ the higher the value of $R S$ and vice versa.

The linear boundary of the concrete material under compression is about $40 \%$ of its maximum load capacity [12]. When it is attributed to the residual strength of load $(R S)$ then this corresponds to the value of $60 \% R S$. If this value is adopted as a lower boundary of the residual strength of the load and it is classified as "good" quality concrete then the pulse velocity value can be determined using the corresponding line of the lower and upper limit lines. The lower and upper limit line is the trend line data of the specimens with a $90 \%$ level of confidence as clearly shown in Fig. 5.

Based on this approach, for $60 \% R S$, a lower $v$ of 3.7 and the higher one of 4.3 in terms of the direct method is found. This can be explained as follows. When the $R S$ increased by $20 \%$ as the maximum range of the "good" classification, then line $v$ of 3.7 is drawn parallel to the $y$-axis until $80 \% R S$, then drawn parallel to the $\mathrm{x}$-axis. This line intersects the upper boundary line of $80 \% R S$ corresponding to $v$ of 4.3 . This is clearly shown in Fig. 5(a) by the dark shade between $60 \%$ and $80 \% R S$.

Of course when $R S$ is higher than $80 \%$ then this concrete is classified as "Excellent" quality. For $R S$ between $40 \%$ and $60 \%$, it is classified as "doubtful", while a $R S$ between 20 and 40 is classified as "poor" and a $R S$ less than $20 \%$ is classified as "very poor". Thus, 
from each classification the values of $v$ which is corresponded with the $R S$ values can be drawn as shown in Fig. 5.

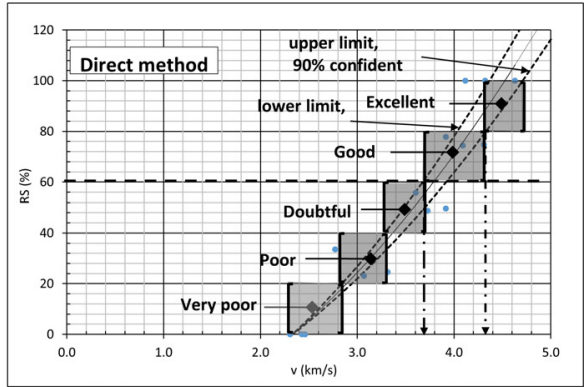

(a)

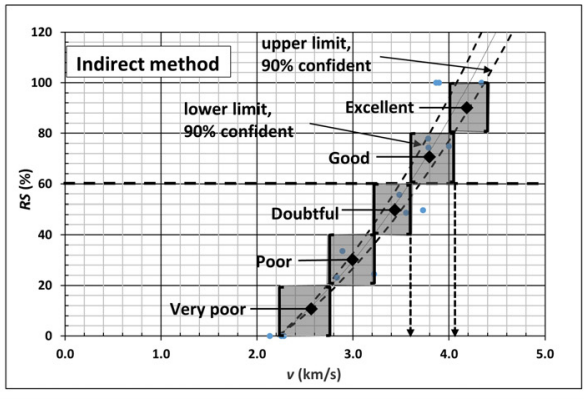

(b)

Fig. 5. Concrete classification on the basis of pulse velocity: (a) direct method; (b) indirect method

Fig. 5 above can be simplified in the list form and presented alongside the classification of concrete quality based on the reference [10] as presented in Table 4 . The direct test method gives $v$ values higher than that of the indirect method. As the $v$ value of the reference is measured using the direct method, column (2) of Table 4, this paper will directly compare the $v$ obtained by the direct method in this experiment with the $v$ of the reference.

Table 4. Resume of concrete quality on the bases of pulse velocity

\begin{tabular}{|c|c|c|c|c|c|c|c|}
\hline \multirow{3}{*}{$\begin{array}{c}\text { Concrete } \\
\text { quality }\end{array}$} & \multirow{2}{*}{\multicolumn{2}{|c|}{$\begin{array}{l}\text { Pulse velocity }[10] \\
(\mathrm{km} / \mathrm{s})\end{array}$}} & \multicolumn{4}{|c|}{ Pulse velocity $(\mathrm{km} / \mathrm{s})$} & \multirow{3}{*}{$\begin{array}{c}\text { Residual } \\
\text { strength, } R S \\
(\%)\end{array}$} \\
\hline & & & \multicolumn{2}{|c|}{ Direct method } & \multicolumn{2}{|c|}{ Indirect method } & \\
\hline & $\mathbf{v}$ & range & $\mathbf{v}$ & range & $\mathbf{v}$ & range & \\
\hline (1) & (2) & (3) & (4) & (5) & (6) & (7) & (8) \\
\hline excellent & $>4.5$ & $\sim$ & $>4.4$ & $\sim$ & $>4.2$ & $\sim$ & $>80$ \\
\hline good & $3.5-4.5$ & 1.0 & $3.7-4.4$ & 0.7 & $3.6-4.1$ & 0.5 & $60-80$ \\
\hline doubtful & $3.0-3.5$ & 0.5 & $3.3-3.7$ & 0.4 & $3.2-3.6$ & 0.4 & $40-60$ \\
\hline poor & $2.0-3.0$ & 1.0 & $2.9-3.3$ & 0.4 & $2.8-3.2$ & 0.4 & $20-40$ \\
\hline very poor & $<2.0$ & $\sim$ & $<2.9$ & $\sim$ & $<2.8$ & $\sim$ & $<20$ \\
\hline
\end{tabular}

It is clear from the table that for a classification of "good" concrete quality, pulse velocity recorded of the direct method has a value with a narrower range when compared to the reference range value which is 0.7 and 1 respectively. If this range value is adopted then the assessment or interpretation of the structural safety would be more convenient, since the lower limit measured is higher than that of the reference lower limit value. This applies also to all concrete quality classifications.

Furthermore, from the available data, the regression for the $R S$ value with the compressive strength, $f_{c}$ ' and pulse velocity, $v$, is created and this generates Eq. (8) and Eq. (9) for the direct and indirect methods respectively. These equations are valid for $0<R S \leq$ 100.

$$
\begin{aligned}
& R S=47.82 v_{d}-1.100 f_{c}^{\prime}-79.699 \\
& R S=50.75 v_{i}-0.899 f_{c}^{\prime}-86.975
\end{aligned}
$$

where $R S$ is residual strength $(\%), f_{c}^{\prime}$ is compressive strength (MPa), $v_{\mathrm{d}}$ is a direct reading of pulse velocity $(\mathrm{km} / \mathrm{s})$ and $v_{\mathrm{i}}$ is an indirect reading of pulse velocity (MPa). 
To clarify the relationship between $R S$ and variable $f_{c}^{\prime}$ and $v$, these equations are illustrated in the $3 \mathrm{D}$ plot such as in Fig. 6(a) and Fig. 6(b) with respect to a direct and indirect method of $v$ value.

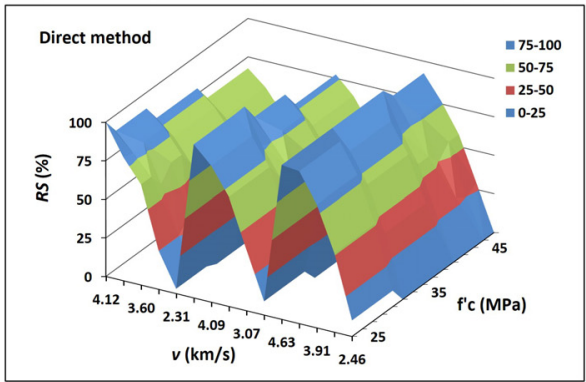

(a)

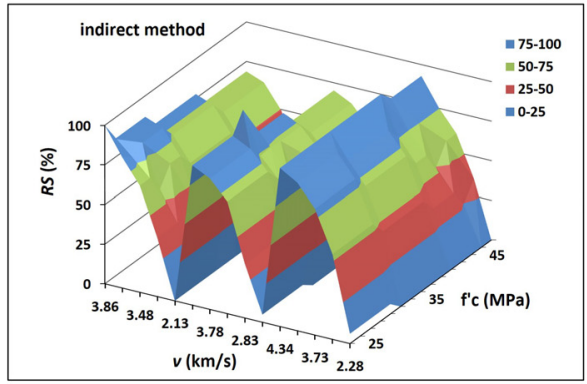

(b)

Fig. 6. Contour plot for $R S$ against $v$ and $f_{c}^{\prime}$ : (a) direct method and (b) indirect method

\subsection{Structure representation}

To represent the condition of the structure in the field, the reinforced concrete beams under flexural loading are considered. The UPV is applied to the beam at the time it is loaded to represent the measurement of $v$ during real conditions. Fig. 7 shows the results obtained when the specimen was measured under flexural loading.

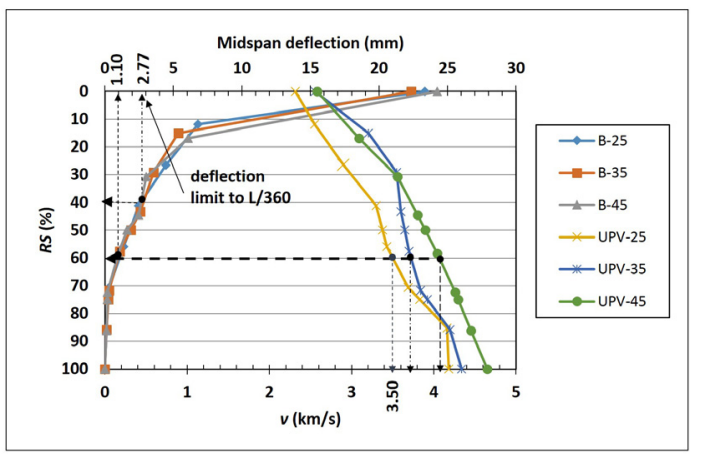

Fig. 7. Interpretation of beam condition

As it is already accepted that $60 \%$ of $R S$ is the acceptance limit for structures which are considered "good", then at this limit the reading values of $v$ are taken and gives values of $3.5,3.9$, and 4.1 for beams B-25, B-35 and B-45 respectively.

According to Table 4, these measurement results do not agree well with the reference. However, from the flexural test point of view, the graph relationship between $R S$ and deflection show that $60 \% R S$ is acceptable to consider a structure as "good". At this point, the deflection is about $1.1 \mathrm{~mm}$ which is still far away from the allowable deflection of 2.77 $\mathrm{mm}$ taken from $\mathrm{L} / 360$ where $\mathrm{L}$ is an effective span of the beam specimen [14]. It can be seen from the table that interpretation of the structural condition based on both compression and flexural tests lies within the range of $v$ given in the Reference [10]. Therefore, the value of $v$ produced in this study to assess the concrete structure is acceptable. In terms of structural health monitoring, either the $v$ or $R S$ value can be applied to interpret the structure condition. Generally, it can be said that if the $v$ value is above 3.5 and the residual strength $(R S)$ of the structure is $60 \%$ and above, then the structure is considered healthy and still feasible to use. 


\section{Conclusions}

Based on the results and discussions described above, the following conclusions can be drawn.

The NDT method can be used for assessment and evaluation of structural conditions in the field. The value of $v$ is directly proportional to the load and inversely proportional to the residual strength. Concrete structures with a residual strength of more than $60 \%$ are considered healthy or in a structurally "good" condition. Also, the concrete structure is healthy when the $v$ measured gives a value of 3.5 and above. This value is acceptable and lies within the $v$ range of $3.5-4.5$ given in the reference.

The authors would like to express our gratitude and appreciation to the postgraduate study program of the University of Mataram for the assistance of the research fund.

\section{References}

1. R. L.Wankhade, \& A. B.Landage, Non-destructive testing of concrete structures in karad region. Procedia Eng. 51, 8-18 (2013).

2. K. L. Rens, \& P. E. Terry, Review of nondestructive evaluation techniques of civil infrastructure. J. Perform. contructed Facil. 11, 152-160 (1997).

3. G. Pascale, A. Di Leo, \& V.Bonora, Nondestructive Assessment of the Actual Compressive Strength of High-Strength Concrete. J. Mater. Civ. Eng. 15, 452-459 (2003).

4. W. P. S. Dias, \& A. D. C. Jayanandana, Condition assessment of a deteriorated cement works. J. Perform. Constr. Facil. 17, 188-195 (2003).

5. T. Parthiban, R. Ravi, \& G. T. Parthiban, Potential monitoring system for corrosion of steel in concrete. Adv. Eng. Softw. 37, 375-381 (2006).

6. D. Breysse, G. Klysz, X. Dérobert, C. Sirieix, \& J. F. Lataste, How to combine several non-destructive techniques for a better assessment of concrete structures. Cem. Concr. Res. 38, 783-793 (2008).

7. S. K. Verma, S. S. Bhadauria, \& S. Akhtar, Review of Nondestructive Testing Methods for Condition Monitoring of Concrete Structures. J. Constr. Eng. 2013, 1-11 (2013).

8. J. Helal, M. Sofi, \& P. Mendis, Non-destructive testing of concrete: A review of methods. Electron. J. Struct. Engnr 14, 97-105 (2015).

9. J. M. W. Brownjohn, Structural health monitoring of civil infrastructure. Philos. Trans. R. Soc. A Math. Phys. Eng. Sci. 365, 589-622 (2007).

10. IAEA, Guidebook on non-destructive testing of concrete structures. Train. Course Ser. 17, 231 (2002).

11. SNI, The procedure of mixing selection for normal concrete, heavy concrete and mass concrete (in Bahasa), 7656, (2012).

12. ASTM C 469-02, Standard Test Method for Static Modulus of Elasticity and Poisson's Ratio of Concrete, 4, pp. 1-5, (2013).

13. A. Akmaluddin, Utilising NDT apparatus for strength assessment of the concrete structural element, Rekayasa, 9, 93-98, (2008).

14. A. Akmaluddin, Effect of Tensile Reinforcement Ratio on the Effective Moment of Inertia of Reinforced Lightweight Concrete Beams for Short Term Deflection Calculation, ITB J. Eng. Sci., 43, 209-226, (2011). 